\title{
Emotional Labor and Place Attachment in Rural Tourism: The Mediating Role of Perceived Authenticity
}

\author{
Yunxia Shi ${ }^{1}$, Rumeng Zhang ${ }^{1} \&$ Chunhao $\mathrm{Ma}^{1}$ \\ ${ }^{1}$ Shandong Technology and Business University, China \\ Correspondence: Chunhao Ma, Shandong Technology and Business University, No.191, Laishan District, Yantai \\ City, Shandong Province, China. E-mail: machunhoo@163.com
}

Received: August 5, $2021 \quad$ Accepted: September 8, 2021 Online Published: September 14, 2021

doi:10.5539/ijms.v13n3p33 URL: https://doi.org/10.5539/ijms.v13n3p33

\begin{abstract}
Place attachment can effectively increase the revisit rate of tourists, which is significant for the sustainability of rural tourism. However, previous studies have rarely explored what kind of host-guest emotional closeness can promote tourist place attachment. This study explores the relationship between local residents' emotional labor strategy, perceived authenticity, and tourists' place attachment based on the rural tourism context. A total of 266 valid questionnaires were collected from rural tourists in Yantai as the research subjects by random sampling method. Structural equation modeling was applied to test the hypotheses. The results showed that local residents' deep acting positively influenced tourists' place attachment, and perceived authenticity partially mediated the relationship between the two. The negative effect of surface acting on rural tourists' place attachment was not significant.
\end{abstract}

Keywords: emotional labor, rural tourism, place attachment, authenticity

\section{Introduction}

Rural tourism refers to tourists going to rural areas to visit natural attractions, such as villages, farms, heritage (Irvine \& Anderson, 2004). Facing the pressure of fast-paced work in the city, more and more people choose to do rural tourism to find a simple rhythm of life, so as to obtain a sense of well-being and a higher quality of life (Kastenholz et al., 2018). As competition in the tourism market intensifies, cultivating tourists' local attachment is gradually being emphasized by tourism-related practitioners. Place attachment is defined as an emotional, cognitive and behavioral-based connection between a visitor and a destination (Hidalgo \& Hernandez, 2001). Place attachment can be effective in increasing customer loyalty, which leads to increased revisit rates and market share (Tsai, 2012; Chen \& Dwyer, 2018). Therefore, it is important for both destinations and tourists to find out what factors influence the place attachment. Previous studies have found that travel motivation, involvement, and perceived attractiveness can significantly influence place attachment (Prayag \& Ryan, 2012; Vada et al., 2019). However, few studies have examined the impact of emotional labor performed by residents of tourist destinations.

It is important to examine the issue of emotional labor of local residents. This is because, compared to other forms of tourism, local residents play an essential role in rural tourism. On the one hand, there is a high level of participation from local residents in the rural tourism process. For example, they open farmhouses and engage in the production and sale of traditional handicrafts and local specialties. They are important providers of local tourism services as well as disseminators of local social landscape and tourism stakeholders (Ramkissoon, 2015). On the other hand, in rural tourism, tourists pay more attention to experiencing the local human culture and the living condition of residents. Local residents, as part of the local tourism attraction, have become an important factor influencing the tourists' perception of the culture of the destination (Scannell \& Gifford, 2017).

Local residents, as community participants in tourism, need to use certain strategies to manage their emotional expressions, which are called emotional labor (Hochschild, 1983). They usually suppress negative emotions and show positive emotions to the tourist to make them feel at home (Lechner \& Paul, 2019). Emotional labor is often considered to consist of two strategies, surface acting, in which individuals deliberately control their facial muscles to display positive emotions, and deep acting, in which individuals naturally display positive emotions from the inside out by changing their internal perceptions (Grandey, 2003). This study distinguishes between these two strategies and examines the impact of local residents' emotional labor on place attachment. In addition, 
previous studies have found that authenticity has a significant positive effect on tourists' place attachment (Vada et al., 2019). In the context of rural tourism, the emotional labor performed by local residents has an important influence on the production of authenticity and thus may have a role in local attachment (Kolar \& Zabkar, 2010). Therefore, this study introduces the authenticity as a mediating variable to explore the process mechanism between local residents' emotional labor and tourists' place attachment.

In summary, this study improves on previous research related to rural tourism in the following ways. First, based on the emotional labor perspective, this study examines the effect of local residents' emotional labor strategies (surface acting vs. deep acting) on tourists' place attachment. Second, this study explored the process mechanisms of emotional labor on place attachment and examined the mediating role played by authenticity. Finally, the study from the receiver perspective of emotional labor not only responds to the calls made by scholars such as Groth et al. (2009), but also makes a contribution to the development of related theories.

\section{Literature Review and Hypothesis}

\subsection{Emotional Labor Theory}

Hochschild introduced the concept of emotional labor based on his study of flight attendants. Emotional labor has been defined as a front-line employee getting paid or tipped by managing his or her emotions and performing to the customer in accordance with the organization's requirements for the face or body (Hochschild, 1983). Early studies mainly applied emotional labor theory to the service industry (Grandey, 2003), but later studies found that emotional labor also existed in other contexts, such as between colleagues and leaders and subordinates in the workplace (Gabriel et al., 2020). At the core of emotional labor is an effort to adjust to emotions, which involves two strategies, deep acting and surface acting. Deep acting is a pre-focused emotion regulation strategy that involves adjusting inner feelings and then expressing the positive emotions required by the organization, as expressed in facial expressions, voice tone, gestures and body posture (Lechner \& Paul, 2019). In contrast, surface acting is reaction-focused, simply adjusting the emotional expression to show positive emotions without changing the true feelings inside (Groth et al., 2009).

Grandey and Melloy (2017) point out that the study of emotional labor requires the integration of certain socio-cultural contexts. In fact, in the process of rural tourism, local residents are often required to perform emotional labor. For example, when explaining local history, culture and customs to tourists, they need to mobilize their inner emotions and thus perform paid or unpaid emotional labor. However, existing studies lack the impact of emotional labor for local residents in rural tourism contexts.

In particular, it should be noted that the emotional labor of residents as perceived by tourists and their own emotional labor as perceived by residents are two different concepts (Groth et al., 2009). The visitor plays a leading role in establishing the boundaries of the host-guest emotional interaction. In other words, the emotional labor felt by visitors is more important. Therefore, this study selects tourist-perceived emotional labor as the independent variable to investigate the effect of resident' emotional labor on place attachment (Gong, 2020).

\subsection{Place Attachment}

The concept of place attachment was first derived from attachment theory in environmental psychology and refers to the emotional connection between people and places (Hidalgo \& Hernandez, 2001). Attachment theory suggests that people become attached to a place if they associate social interactions that occur in that place with their associated meaning, or if they thereby develop a common emotional bond with that place (Strzelecka et al., 2017). Scholars have used it as a construct to measure the emotional, functional, affective, and social associations that tourists have with a destination or tourism product (Ramkissoon, 2015).

Place attachment is divided into four dimensions, which are place identity, place dependence, emotional attachment and social connection (Han et al., 2019). Among these, place identity represents the individual's cognitive identification with the natural environment. Place dependence refers to a functional attachment to a place, emphasizing the importance of social and natural resources. Emotional attachment refers to the emotional relationship between an individual and a place that goes beyond cognition. Social connection refers to the relationships between people, communities and cultures, and focuses on the experience of social interaction between people in a particular place. The four-dimensional division approach takes into account the interaction between people and places in addition to focusing on the interaction between people and places (Scannell \& Gifford, 2017). Rural tourism is mainly based on natural or rustic elements as tourism attraction, and tourists' place attachment includes both the geographic perspective of place attachment dimension and the emotional closeness between the host and the guest. Therefore, this paper adopts the four-dimensional division of place attachment referred to Han et al. (2019). 


\subsection{Local Residents' Emotional Labor and Tourists' Place Attachment}

Expectation failure theory states that consumers compare their post-consumption performance with their pre-consumption expectations as a way to determine whether they are satisfied with a product or service (Kaminakis et al., 2019). Before traveling, tourists look ahead in their minds to the upcoming trip, creating expectations and imagination. During the traveling, tourists assess the experience of interacting with local residents. Tourists may become emotionally attached to this tourist destination because of the emotional labor of the residents. Thus, when local residents use two emotional labor strategies to engage with tourists, they trigger an emotional response and produce an emotional infection (Van-Kleef, 2012).

Tourists will assess the situation through a certain reasoning process. If the resident behaves sincerely (deep acting), it will be perceived as an out-of-role behavior that is beyond their expectations. This can make a positive emotional experience of the destination for tourists, which leads to place attachment. On the contrary, if tourists perceive the performance of local residents as false (surface acting), it will lead to a negative disconfirmation, destroying the emotional experience and reducing place attachment (Grandey, 2003). Based on the above analysis, the following hypotheses are proposed:

H1a: Local residents' surface acting negatively influences tourists' place attachment.

H1b: Local residents' deep acting positively influences tourists' place attachment.

\subsection{The Mediation Effect of Authenticity}

MacCannell (1973) first applied the concept of authenticity to the field of tourism research, arguing that the search for authenticity is a tourist's motivation to travel. Since then, a great deal of attention has been paid to the study of authenticity in the field of tourism. At present, authenticity remains a complex and controversial concept. Objectivist authenticity is usually seen as the original backstage reality of the object (Wang, 1999). Constructivism sees authenticity as a judgment, belief, and meaning, and emphasizes commodified authenticity, such as hyper-authentic context and pseudo-backstage (Cole, 2007). Existentialism holds that authenticity does not depend on objective objects, but refers to personal or individual emotions activated through the process of travel (Kolar \& Zabkar, 2010). The three forms of authenticity in the tourism environment are interrelated and therefore none of them should be dismissed.

In tourism, authenticity is usually evaluated by tourists. Therefore, the value of authenticity depends on the tourists' perception and evaluation of the experience (Ramkissoo, 2015). Authenticity in this study refers to the degree to which guests feel authentic, genuine and inspiring in the accommodation environment (Lucas, 2002). It is perceived and assessed based on tangible elements (e.g., the provision of meals, accommodations, and entertainment) and intangible elements (e.g., the host-guest relationship). As the tourism activities progressed, most of the local residents were able to use their emotional skills to interact with tourists. How does their emotional labor influence the authenticity perceived by tourists? First, tourists have the ability to distinguish between sincere and false emotional labor (Grandey \& Melloy, 2017). Tourists can discern the authenticity of emotional labor and thus form a perception of the authenticity of a tourist destination (Lechner \& Paul, 2019). Therefore, the two emotional labor strategies of local residents (i.e., surface acting and deep acting) can affect tourists' perception of the authenticity of the destination to varying degrees. It has been shown that authenticity has a significant impact on visitor satisfaction, destination image, and place perception (Engeset \& Elvekrok, 2015). Thus, local residents' emotional labor is likely to have an impact on place attachment through perceived authenticity. Based on the above analysis, the following hypotheses are proposed:

H2a: Perceived authenticity plays a mediation role between local residents' surface acting strategy and tourists' place attachment;

H2b: Perceived authenticity plays a mediation role between local residents' deep acting strategy and tourists' place attachment.

In summary, the conceptual model of this study is shown in Figure 1. 


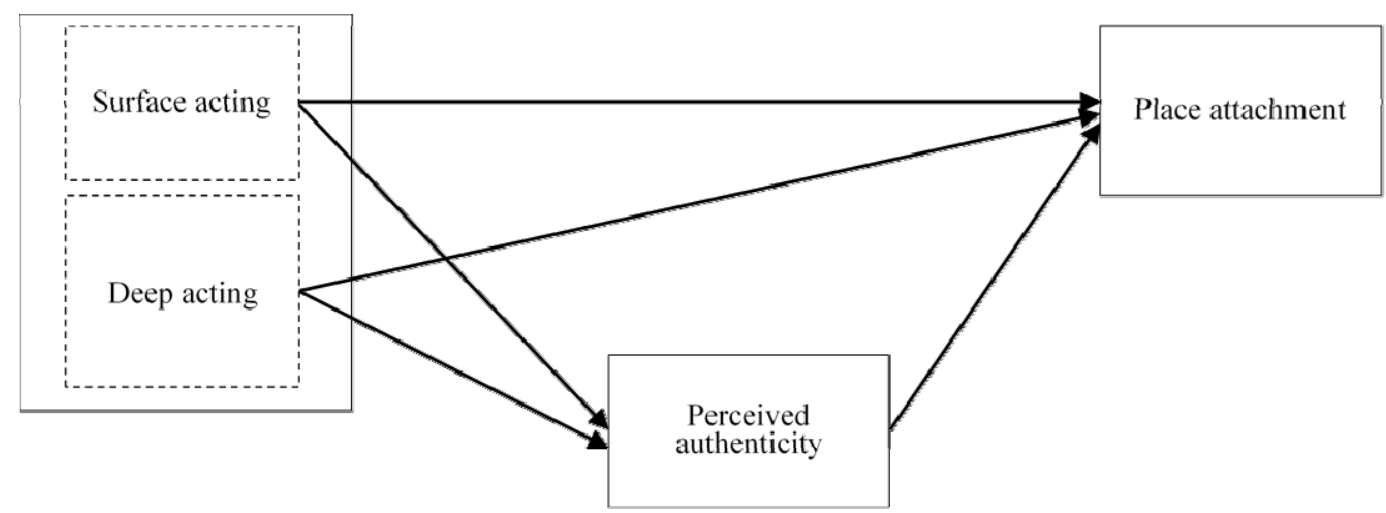

Figure 1. Conceptual model

\section{Methodology}

\subsection{Sample and Data Collection}

The sample data used in this study were collected in Yantai, China. Yantai is a well-known rural tourism city. The participation rate of local residents in rural tourism is high. For example, in the vicinity of rural tourism scenic spots, local residents sell special products such as cherries, apples, seafood and handicrafts that they grow.

A pre-study was conducted in July 2019 in order to make the questionnaire clear and well-structured. 16 graduate students were randomly invited to conduct a small-scale study, and the results showed that the questionnaire had good reliability and validity. We conducted the formal research from July to September 2019, by distributing questionnaires through offline paper-based methods and online communication tools. A total of 266 valid questionnaires were collected after excluding invalid questionnaires such as incomplete responses. The results of Harman's one-way test showed that the variance explained by the first common factor was $34.1 \%$, indicating that there was no serious common method bias. The statistical information of the research subjects is shown in Table 1.

Table 1. Sample statistical information

\begin{tabular}{llllllll}
\hline \multicolumn{2}{l}{ Variable Group } & Frequency & $(\%)$ & Variable Group & & Frequency & $(\%)$ \\
\hline \multirow{4}{*}{ Gender } & Female & 108 & 40.6 & First time to come & Yes & 126 & 47.4 \\
& Male & 158 & 59.4 & & No & 140 & 52.6 \\
& $18-25$ & 32 & 12 & Local or not & Yes & 217 & 81.6 \\
& $26-35$ & 77 & 28.9 & & No & 49 & 18.4 \\
& $36-45$ & 80 & 30.1 & Income & Below 2000 & 31 & 11.6 \\
& $46-55$ & 43 & 16.2 & & $2001-3500$ & 84 & 31.6 \\
& Above 55 & 34 & 12.8 & & $3501-6000$ & 93 & 35.0 \\
& & & & & Above 6000 & 58 & 21.8 \\
\hline
\end{tabular}

\subsection{Scale Design}

To ensure reliability and validity, a well-established scale in the field of management was used for this study. To ensure that the content and structure of the questionnaire were sound, we conducted translation and back-translation with the assistance of English professors. Then, we randomly distributed the test questionnaire and revised it based on the feedback to form the final scale. All questionnaires were based on a 5-point Likert scale $(1=$ completely disagree, $5=$ completely agree $)$.

The items of surface acting and deep acting were referred to Grandey (2003), with three questions for each variable, such as "The local residents deal with me as if she is acting" and "The local residents struggle to feel the emotions she needs to show me". The items of perceived authenticity were referred to Wang (1999), with three questions, such as "I enjoyed a unique spiritual experience". The items of place attachment were referred to Ramkissoon (2015), with three items of place identity, four items of emotional attachment, and three items of social connection, such as "I have a strong sense of belonging to this place", "The local residents give me a good feeling", "This enhances my travel experience". 


\section{Data Analysis}

\subsection{Reliability and Validity}

This study was examined with the support of SPSS 21.0 and AMOS software. Structural equation modeling was used to analyze the relationship between constructs, and all constructs were measured using reactivity indicators, as shown in Table 2. The alpha coefficients for surface acting, deep acting, perceived authenticity, and place attachment were $0.648,0.762,0.871$, and 0.709 , respectively, all of which were greater than 0.6 , indicating that the scales had good reliability. In addition, the factor loadings of each question item were greater than 0.5 and the AVE values were greater than 0.5 , indicating that the convergent validity of the scale was good.

Table 2. Indicators' reliability and validity

\begin{tabular}{|c|c|c|c|c|c|}
\hline Variable & Item & Factor loading & $\alpha$ & AVE & $\mathrm{CR}$ \\
\hline \multirow[t]{3}{*}{ SA } & sa1 & 0.779 & 0.648 & 0.588 & 0.810 \\
\hline & sa2 & 0.749 & & & \\
\hline & sa3 & 0.772 & & & \\
\hline \multirow[t]{3}{*}{ DA } & da1 & 0.813 & 0.762 & 0.677 & 0.863 \\
\hline & $\mathrm{da} 2$ & 0.823 & & & \\
\hline & da3 & 0.832 & & & \\
\hline EL & & & 0.677 & 0.632 & 0.812 \\
\hline \multirow[t]{3}{*}{ RA } & ra1 & 0.826 & 0.871 & 0.576 & 0.872 \\
\hline & $\mathrm{ra} 2$ & 0.788 & & & \\
\hline & $\mathrm{ra} 3$ & 0.769 & & & \\
\hline \multirow[t]{14}{*}{ PA } & pa1 & 0.72 & 0.709 & 0.795 & 0.775 \\
\hline & pa2 & 0.711 & & & \\
\hline & pa3 & 0.899 & & & \\
\hline & pa4 & 0.775 & & & \\
\hline & pa5 & 0.729 & & & \\
\hline & pa6 & 0.733 & & & \\
\hline & pa7 & 0.698 & & & \\
\hline & pa8 & 0.78 & & & \\
\hline & pa9 & 0.743 & & & \\
\hline & pa10 & 0.749 & & & \\
\hline & pa11 & 0.766 & & & \\
\hline & pa12 & 0.781 & & & \\
\hline & pa13 & 0.727 & & & \\
\hline & pa14 & 0.88 & & & \\
\hline
\end{tabular}

Note. $* \mathrm{SA}=$ surface acting, $\mathrm{DA}=$ deep acting, $\mathrm{EL}=$ emotional labor, $\mathrm{PA}=$ perceived authenticity, $\mathrm{PA}=$ place attachment.

We conducted confirmatory factor analysis (CFA) by using AMOS and examined the fit indices of the hypothesized four-factor model. Table 3 shows that the hypothesized model fit the data well. Most values of the correlation coefficients between the independent variables were below the cut-off value of 0.7 . The composite reliability (CR) of each construct ranged from 0.81 to 0.98 . The square root of AVE of each construct was greater than its correlations with other constructs (see Table 4). This indicates good discriminant validity of the scales.

Table 3. Confirmatory factor analysis

\begin{tabular}{lllllll}
\hline Fit index & $\chi^{2} / \mathrm{df}$ & RMSEA & NFI & RFI & IFI & TLI \\
\hline Standard & $(<3.000)$ & $(<0.080)$ & $(>0.900)$ & $(>0.900)$ & $(>0.900)$ & $(>0.900)$ \\
Value & 1.17 & 0.003 & 0.93 & 0.93 & 0.99 & 1.000 \\
\hline
\end{tabular}

Table 4. Correlations among variables

\begin{tabular}{lllll}
\hline & SA & DA & RA & PA \\
\hline SA & $\mathbf{0 . 6 6 7}$ & & & \\
DA & 0.004 & $\mathbf{0 . 6 2 3}$ & & \\
RA & -0.003 & $0.608^{* *}$ & $\mathbf{0 . 5 9 9}$ & \\
PA & -0.038 & $0.609^{* *}$ & $0.558^{* *}$ & $\mathbf{0 . 6 7 5}$ \\
\hline
\end{tabular}

Note. ${ }^{*} \mathrm{p}<.05 ; * * \mathrm{p}<.01$ (two-tailed). Boldface letter is the square root of AVE. 


\subsection{Hypotheses Testing}

According to Pearson's correlation analysis, the relationship between residents' emotional labor strategy and tourists' place attachment is shown in Table 4. It shows that they are inter-correlated among deep acting, relational authenticity and place attachment. The maximum likelihood estimation (MLE) method can be used to evaluate the structural equation when the number of research samples greater than 100 . The path analysis results are shown in Figure $2\left(\chi^{2}=11.87, \mathrm{df}=18, \chi^{2} / \mathrm{df}=0.659, \mathrm{CFI}=1.000, \mathrm{PNFI}=0.493\right.$, RMSEA $\left.=0.000\right)$. The path coefficient from surface acting to place attachment was -0.05 ( $\mathrm{p}=0.363$, not significant), not support H1a. The path coefficient of deep acting to place attachment was 0.93 ( $\mathrm{p}<0.001$, significant), H1b was supported.

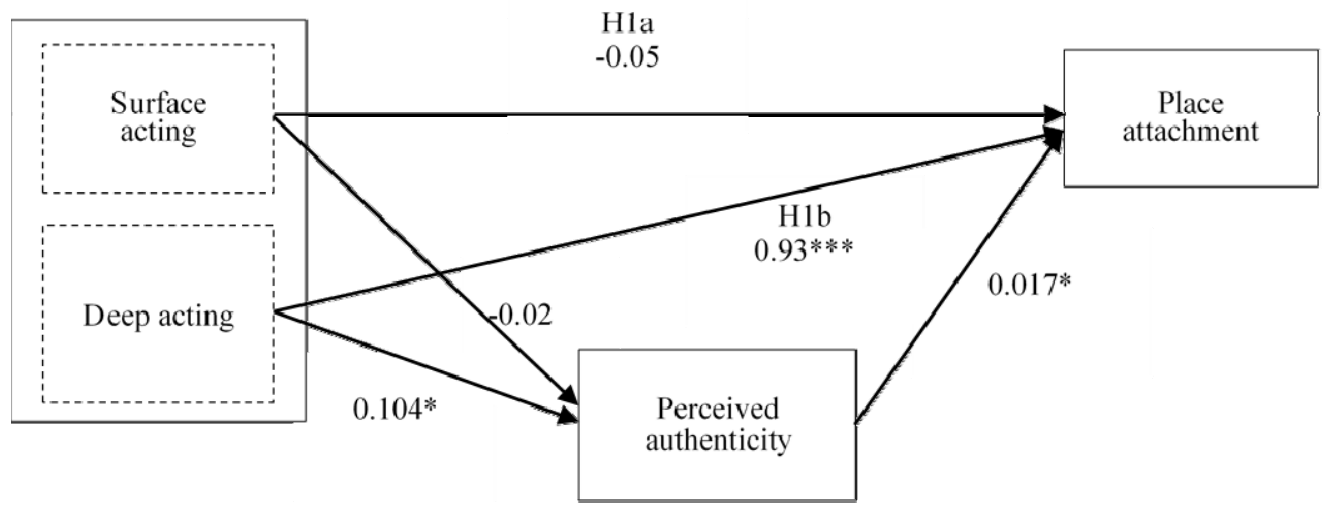

Figure 2. Structural equation model

Bootstrap method was used to test the mediation effect. Through bootstrap 2000 sampling and maximum likelihood method operation, the overall effect and direct effect among variables were shown in Table 5 $\left(\chi^{2}=60.028, \mathrm{df}=60, \chi^{2} / \mathrm{df}=1.000, \mathrm{CFI}=1.000, \mathrm{PNFI}=0.738, \mathrm{RMSEA}=0.002\right)$. It indicates that the mediation effect of relational authenticity between surface acting and place attachment is not significant. So H2a is not supported. Deep acting has a significant effect on relational authenticity, and relational authenticity has a significant effect on place attachment, so we controlled the mediation variable (relational authenticity) to test the impact of deep play on place attachment. The results showed that the effect of deep acting on place attachment decreased significantly $(\beta=0.913, p<0.05)$, indicating that relational authenticity played a partial mediation effect between deep acting and place attachment. So H2b was supported.

Table 5. Total and direct effect

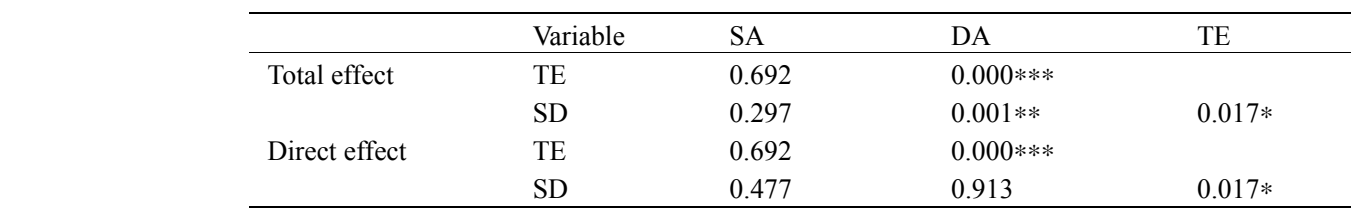

Note. ${ }^{*} \mathrm{p}<.05 ; * * \mathrm{p}<.0 \overline{1 ; * * \mathrm{p}<.001 .}$

\section{Discussion}

This study validates our theoretical model by analyzing 266 valid questionnaires collected in Yantai. The empirical studies showed that local residents' deep acting positively influenced tourists' place attachment, and perceived authenticity partially mediated the relationship between the two. The negative effect of surface acting on rural tourists' place attachment was not significant.

\subsection{Research Conclusions}

In rural tourism, local residents play an important role. This study proposes a framework for the relationship between local residents' emotional labor strategies, the authenticity of the host-guest relationship, and tourists' place attachment, and tests the relationship between the three. The findings of this study are as follows.

First, the deep acting strategies of local residents have a positive effect on tourists' place attachment. This is 
consistent with the findings of previous studies. For example, Lechner and Paul (2019) found that customers perceive that the deep acting of employee positively influences customer loyalty. In this study, tourists played the role of customers, and local residents played the role of service employees. The findings suggest that authenticity induced by deep acting is interpreted as a genuine concern for the customer.

Second, authenticity plays a partially mediating role between deep acting and place attachment. Specifically, in a rural tourism context, local residents who perform emotional labor using deep acting strategies significantly increase tourists' perceptions of authenticity, which in turn increases tourists' place attachment.

Third, neither the direct effect of surface acting on tourists' place attachment nor the indirect effect on place attachment through authenticity was significant, which is inconsistent with previous research findings. This paradox can be explained by the optimism principle: tourists come to the countryside to relax and therefore will tend to focus on more positive information. In fact, emotional labor does not always lead to negative or positive outcomes due to situational differences (Grandey \& Mello, 2017). In the present study, tourists may have perceived surface acting as an in-role behavior that did not result in a significant decrease in expectations (Lechner \& Paul, 2019). Thus, the surface acting strategy did not reduce tourists' place attachment.

\subsection{Theoretical Implications}

The theoretical contributions of the present study are as follows.

First, this study enriches the antecedent studies of place attachment. Most of the previous studies on place attachment have been explored from the perspectives of tourism motivation and tourism involvement (Prayag \& Ryan, 2012; Vada et al., 2019), and less attention has been paid to the influence brought by local residents. This study fills the gap to a certain extent by confirming that the emotional labor of local residents has an important impact on place attachment.

Second, this study introduces the emotional labor theory into the context of rural tourism, expanding the scope of theory use and further developing the emotional labor theory. Most previous research on emotional labor has centered on the hotel industry (Grandey, 2003), and organizational contexts (Gabriel et al., 2020). Even in the exploration of the tourism industry, the relevant literature has focused on tour guides and discussed the impact that the emotional labor of service workers such as tour guides has on tourists (Mackenzie \& Raymond, 2020), while ignoring the importance of local residents. In fact, the role played by local residents as an important component of the tourism process is also profound.

Third, it deepens the understanding of authenticity and opens the "black box" in which the emotional labor of local residents affects tourists' place attachment. This study innovatively introduces relational authenticity as a mediating variable and explores its mediating effect, which is instructive for related studies.

\subsection{Practical Implications}

In the era of experience economy, the demand for tourism has changed to in-depth experience. The role of local residents becomes more and more important. Therefore, rural tourism enterprises need to change their development concept based on the original foundation, conform to the new normal of tourism market development, make cultivating tourists' place attachment the focus of their work, and strive to achieve sustainable development of rural tourism.

First, managers should play a leading role in rural tourism, establish a scientific and reasonable benefit sharing mechanism, and give back part of the local tourism income to local residents to give them a certain sense of support and access (Irvine \& Anderson, 2004). Raise residents' awareness of rural tourism through education and training so that they recognize that their emotional expression is also a tourism resource. Residents are encouraged to take a proactive role in the emotional labor process and create value with tourists.

Second, in the process of rural tourism development, attention should be paid to retaining the authenticity of rural culture. According to the different stages of tourism development, local tourism elites are cultivated and local people are allowed to fully participate. Ensuring the moderate authenticity of rural tourism can also improve the overall human capital of the destination and safeguard the subjectivity of the residents. Involve local residents in tourism operations to make destination development more standardized

\subsection{Limitations}

Limitations are inevitable. In this study, questionnaire data are all from Yantai, China. Further research is needed to test whether they are applicable to other regions. This study explores the mediating mechanism of the authenticity, and there may be other mediating or moderating variables that may also play an influential role. For example, the level of involvement affects tourists' perceptions of authenticity (Tiberghien et al., 2020). These 
factors can be taken into account in the future to construct a more complete research model.

\section{Acknowledgments}

This project supported by the National Social Science Foundation of China (Grant No. 14BGL075) and the Graduate Student Science and Technology Innovation Funding Project of Shandong Technology and Business University.

\section{References}

Chen, N., \& Dwyer, L. (2018). Residents' place satisfaction and place attachment on destination brand-building behaviors: Conceptual and empirical differentiation. Journal of Travel Research, 57, 1026-1041. https://doi.org/10.1177/0047287517729760

Cole, S. (2007). Beyond Authenticity and Commodification. Annals of Tourism Research, 34, 943-960. https://doi.org/10.1016/j.annals.2007.05.004

Engeset, M. G., \& Elvekrok, I. (2015). Authentic Concepts Effects on Tourist Satisfaction. Journal of Travel Research, 54, 456-466. https://doi.org/10.1177/0047287514522876

Gabriel, A. S., Koopman, J., \& Rosen, C. C. (2020). Are Coworkers Getting into the Act? An Examination of Emotion Regulation in Coworker Exchanges. Journal of Applied Psychology, 105, 907-929. https://doi.org/10.1037/apl0000473

Gong, T., Park, J. K., \& Hyun, H. (2020). Customer Response Toward Employees' Emotional Labor in Service Industry Settings. Journal of Retailing and Consumer Services, 52, 101899. https://doi.org/10.1016/j.jretconser.2019.101899

Grandey, A. A. (2003). When "The Show Must Go On": Surface Acting and Deep Acting as Determinants of Emotional Exhaustion and Peer-Rated Service Delivery. Academy of Management Journal, 46, 86-96. https://doi.org/10.5465/30040678

Grandey, A. A., \& Melloy, R. C. (2017). The State of the Heart: Emotional Labor as Emotion Regulation Reviewed and Revised. Journal of Occupational Health Psychology, 22, 407-422. https://doi.org/10.1037/ocp0000067

Groth, M., Hennig-Thurau, T., \& Walsh, G. (2009). Customer Reactions to Emotional Labor: The Roles of Employee Acting Strategies and Customer Detection Accuracy. Academy of Management Journal, 52, 958-974. https://doi.org/10.5465/amj.2009.44634116

Han, J. H., Kim, J. S., Lee, C.-K., \& Kim, N. (2019). Role of place attachment dimensions in tourists' decision-making process in Cittáslow. Journal of Destination Marketing \& Management, 11, 108-119. https://doi.org/10.1016/j.jdmm.2018.12.008

Hidalgo, C., \& Hernandez, B. (2001). Place Attachment: Conceptual and Empirical Questions. Journal of Environmental Psychology, 21, 273-281. https://doi.org/10.1006/jevp.2001.0221

Hochschild, A. R. (1983). The Managed Heart: Commercialization of Human Feeling. University of Californica Press, Berkeley, CA.

Irvine, W., \& Anderson, A. R. (2004). Small Tourist Firms in Rural Areas: Agility, Vulnerability and Survival in the Face of Crisis. International Journal of Entrepreneurial Behavior and Research, 10, 229-246. https://doi.org/10.1108/13552550410544204

Kaminakis, K., Karantinou, K., Koritos, C., \& Gounaris, S. (2019). Hospitality Servicescape Effects on Customer-employee Interactions: A Multilevel Study. Tourism Management, 72, 130-144. https://doi.org/10.1016/j.tourman.2018.11.013

Kastenholz, E., Carneiro, M. J., Marques, C. P., \& Loureiro, S. M. C. (2018). The Dimensions of Rural Tourism Experience: Impacts on Arousal, Memory, and Satisfaction. Journal of Travel and Tourism Marketing, 35, 189-201. https://doi.org/10.1080/10548408.2017.1350617

Kolar, T., \& Zabkar, V. (2010). A Consumer-based Model of Authenticity: An Oxymoron or the Foundation of Cultural Heritage Marketing. Tourism Management, 31, 652-664. https://doi.org/10.1016/j.tourman.2009.07.010

Lechner, A. T., \& Paul, M. (2019). Is This Smile for Real? The Role of Affect and Thinking Style in Customer Perceptions of Frontline Employee Emotion Authenticity. Journal of Business Research, 94, 195-208. https://doi.org/10.1016/j.jbusres.2017.06.009 
Lucas, R. (2002). Fragments of HRM in Hospitality? Evidence from the 1998 Workplace Employee Relations Survey. International Journal of Contemporary Hospitality Management, 14, 207-212. https://doi.org/10.1108/09596110210433727

Maccannell, D. (1973). Staged Authenticity: Arrangements of Social Space in Tourist Settings. American Journal of Sociology, 79, 589-603. https://doi.org/10.1086/225585

Mackenzie, S. H., \& Raymond, E. (2020). A conceptual model of adventure tour guide well-being. Annals of Tourism Research, 84, 102977. https://doi.org/10.1016/j.annals.2020.102977

Prayag, G., \& Ryan, C. (2012). Antecedents of Tourists' Loyalty to Mauritius: The Role and Influence of Destination Image, Place Attachment, Personal Involvement, and Satisfaction. Journal of Travel Research, 51,342-356. https://doi.org/10.1177/0047287511410321

Ramkissoon, H. (2015). Authenticity, Satisfaction, and Place Attachment: A Conceptual Framework for Cultural Tourism in African Island Economies. Development Southern Africa, 32, 292-302. https://doi.org/10.1080/0376835X.2015.1010711

Scannell, L., \& Gifford, R. (2017). The Experienced Psychological Benefits of Place Attachment. Journal of Environmental Psychology, 51, 256-269. https://doi.org/10.1016/j.jenvp.2017.04.001

Strzelecka, M., Boley, B. B., \& Woosnam, K. M. (2017). Place attachment and empowerment: Do residents need to be attached to be empowered? Annals of Tourism Research, 66, 61-73. https://doi.org/10.1016/j.annals.2017.06.002

Tiberghien, G., Bremner, H., \& Milne, S. (2020). Authenticity and Disorientation in the Tourism Experience. Journal of Outdoor Recreation and Tourism, 30, 1-9. https://doi.org/10.1016/j.jort.2020.100283

Tsai, S. P. (2012). Place Attachment and Tourism Marketing: Investigating International Tourists in Singapore. International Journal of Tourism Research, 14, 139-152. https://doi.org/10.1002/jtr.842

Vada, S., Prentice, C., \& Hsiao, A. (2019). The Influence of Tourism Experience and Well-being on Place Attachment. Journal of Retailing and Consumer Services, 47, 322-330. https://doi.org/10.1016/j.jretconser.2018.12.007

Van-Kleef, G. A., Homan, A. C., \& Cheshin, A. (2012). Emotional Influence at Work: Take it EASI. Organizational Psychology Review, 2, 311-339. https://doi.org/10.1177/2041386612454911

Wang, N. (1999). Rethinking Authenticity in Tourism Experience. Annals of Tourism Research, 26, 349-370. https://doi.org/10.1016/S0160-7383(98)00103-0

\section{Copyrights}

Copyright for this article is retained by the author, with first publication rights granted to the journal.

This is an open-access article distributed under the terms and conditions of the Creative Commons Attribution license (http://creativecommons.org/licenses/by/4.0/). 